\title{
Mildly Abnormal Ejection Fraction
}

National Cancer Institute

\section{Source}

National Cancer Institute. Mildly Abnormal Ejection Fraction. NCI Thesaurus. Code C99507.

Slightly less than normal amount of blood that is forced from the heart ventricle to produce cardiac output. Quantitatively, the ejection fraction is considered between $40 \%$ to $49 \%$. 